\title{
LOS MALES DE LOS NOMBRAMIENTOS DOCENTES: CUANDO LAS LEYES NO SON UNA EXCUSA ${ }^{1}$
}

\author{
Jimmy Bolaños González \\ Contraloría General de la República \\ San José, Costa Rica
}

Recibido 26-VI-2006 • Aceptado 08-VIII-2006

Resumen: Este ensayo formula un análisis históricojurídico de lo que ha sido el devenir de los últimos cien años en materia de disposiciones relativas a la contratación de personal docente en Costa Rica, sus avances y retrocesos, con vista a garantizar los principios de idoneidad, de igualdad de oportunidades y de profesionalización de los educadores al servicio de la educación pública.

Se enfatiza en el origen no jurídico de los vicios que se presentan en esta materia, sino en la falta de efectividad y cumplimiento de la ley, debido a factores de falta de voluntad política, de arreglos administrativos ineficientes, de falta de recursos y de falta de una formación adecuada de los propios docentes en materia jurídica. Se proponen algunas soluciones sobretodo administrativas y éticas, aunque también una reforma para hacer más operativo y eficaz el accionar del Tribunal de Carrera Docente.

Palabras clave: Nombramientos docentes, Ley de Carrera Docente, Servicio Civil, Registro de elegibles.

\section{Introducción}

Este ensayo busca ahondar en el devenir histórico-jurídico de la contratación de los docentes del Ministerio de Educación Pública en nuestro país, con el fin de poder constatar los vaivenes de su régimen de nombramiento y sobretodo, el largo camino conducente a profesionalizar dicho personal y alejarlo de las prácticas del botín político, el favoritismo y el nepotismo, llegando a determinar algunas conclusiones tendientes a erradicar ese mal y que señalan vías no legales sino administrativas y de control interno para corregirlo.

Para ello, se realizó un estudio de la colección de leyes y decretos de nuestro país, publicada por la Imprenta Nacional, siendo está la fuente primigenia de todo este ensayo, lo mismo que la experiencia del suscrito durante más de 10 años como abogado de la Dirección General de Servicio Civil y cuatro años en el Tribunal de Carrera Docente.

La politiquería en el nombramiento de las plazas docentes es un asunto de muy vieja data, tanto que en el año 1906 se dictó la primera disposición que quiso acabar con tal situación, dotando de estabilidad a los docentes, es decir, ya desde hace 100 años 


\begin{abstract}
This article makes a historic and legal analysis account of the last hundred years legal dispositions, upon rules that regulate public teachers hiring in Costa Rica, its advances and turnovers, aiming at guaranteeing the principles of suitability, equality of opportunities and professionalization of the teachers that work for the public education system.

The non-legal origin of the problems is emphasized, but this does not happen because of different causes, such as: no politic will, institutional problems, lack of resources and, lack of a proper teacher preparation about their rights. The article proposes some administrative and ethic solutions, and also some legal changes in the operation of the Court that judges teachers claims in this matter.
\end{abstract}

Key words: Appointments teachers, Law Career Education, Civil Service, Register eligible. se empezaron a buscar soluciones a esta problemática.

De hecho, con la instauración del Servicio Civil en la segunda mitad del siglo $\mathrm{XX}$ se produjo un avance importante en esta materia, pero aún estamos a mitad de camino de cumplir cabalmente con esta asignatura.

No obstante, no menos cierto es que todavía en los años noventa del siglo pasado quedaban tres grandes reductos del botín político: los diplomáticos, los policías y los docentes. Lo paradójico es que tanto los diplomáticos como los docentes cuentan desde hace más de treinta años con estatutos que regulan el servicio exterior -para los primeros- y la carrera docente -para los segundos-, garantizando los principios, normas y procedimientos propios de un sistema de méritos - cosa que los policías obtuvieron hasta en el año 1994 con el Estatuto Policial-.

Sin embargo, los operadores jurídicos encargados de hacer cumplir tales disposiciones no han podido apartarse completamente de los tentáculos de los políticos de turno y las argucias que utilizan ${ }^{2}$, y se mantienen ciertas prácticas de amiguismo, favoritismo y botín político que no han podido extirparse por ser un mal muy antiguo, arraigado y que se ha resistido a sucumbir.

Para el año 2005 se tienen datos de que el 81,8 por ciento de los docentes trabaja para el Estado, con lo cual, según el I Informe sobre el Estado de la Educación recientemente dado a conocer, son en el concierto de las distintas profesiones "el grupo profesional con una mayor dependencia del empleo público, como cabe esperar por el carácter fundamentalmente público de la enseñanza en Costa Rica”. (pág 9)

Un dato cultural muy arraigado en Costa Rica utilizado como la excusa por excelencia por los administradores de la cosa pública para justificar las cosas que andan mal, ha sido siempre "lanzar una cortina de humo" sosteniendo que el problema reside en la ley y en sus portillos, de manera que 
se concluya que únicamente cambiando la ley se puede arreglar el asunto.

Por lo tanto, es muy fácil decir que la Ley de Carrera Docente es obsoleta porque tiene más de treinta y cinco años, sin identificar y/ahondar en sus defectos, cuando en realidad hay partes de la Ley que "no se han estrenado" -por ejemplo los fines que señala el artículo 53-, o bien que no se aplican ni se han aplicado como debiera según se desarrollará más adelante, ya que sus operadores de una u otra manera han consentido prácticas alejadas de sus principios y disposiciones, acarreando graves males no sólo para el educador sino para la educación en nuestro país en general.

Este ensayo aborda el tema de los nombramientos docentes desde el punto de vista jurídico, administrativo y ético, en relación con los principales males que aquejan esta problemática, para lo cual se empieza urgando en la historia, a partir de las disposiciones reguladoras del siglo XIX pasando al siglo XX, en cuya segunda mitad se produjeron los cambios más significativos con la introducción del Servicio Civil, para lo cual analizaremos las regulaciones vigentes.

Podemos adelantar una conclusión general, cual es que las soluciones primigenias a este problema no pasan por reformas legales, sino que principalmente por cambios administrativos así como de mentalidad y actitud de todos los actores: políticos, autoridades del MEP, Dirección de Personal y Servicio Civil, Tribunal de Carrera Docente, gremios y educadores. Todos tenemos en menor o mayor medida responsabilidad y culpa por no haber hecho lo propio, lo suficiente y necesario por cambiar este estado de cosas, empezando con las autoridades de turno del MEP y se propondrán cambios que tienen que ver con cada uno de esos actores.

\section{Breve recorrido histórico}

A grandes rasgos existen dos períodos históricos bien determinados en esta materia que nos ocupa: uno previo a la implantación del Servicio Civil, que abarca desde el año 1821 a 1952 y otro, a partir de 1953, año en que se promulga la Ley 1581 y empieza a operar el régimen de servicio civil.

\section{Primer período}

Sabemos que nuestro país tempranamente en su vida independiente se preocupó por la educación, primero como un asunto manejado por los municipios, quienes a base de recursos propios y contribuciones de los vecinos financiaban la fundación, construcción de centros educativos y la contratación de educadores, aspectos regulados a nivel infraconstitucional, sea mediante leyes y ordenanzas municipales.

Hay que recordar que durante el mandato de Braulio Carrillo se suspendió el funcionamiento de los municipios, conforme a la Ley de Bases y Garantías de 1841 en que él mismo se declaró Jefe de Estado vitalicio e inamovible, de modo que las escuelas primarias quedaron sin sustento y el Gobierno Central quedó a su recaudo.

No obstante, fue a partir de la Constitución de 1844 en la que por primera vez y en forma novedosa dedica un Título a la educación -el IX-, señalando en dos artículos -el 180 y 181-que "es un sagrado deber del Gobierno poner todos los medios a su alcance para ilustrar al pueblo" y que ese deber significaba un correlativo "derecho de los costarricenses y el Estado la garantiza ... por medio de disposiciones legales", esa misma Ley Fundamental en su artículo 17 también estableció que "todos son admisibles igualmente a los destinos públicos, sin más diferencias que la de sus virtudes y talentos".

Esta base constitucional da pie para que en 1845 se recargara en uno de los dos ministros que existían entonces lo relativo a la Educación y que con fundamento en el artículo 170 de la Constitución de 1847 el Presidente Castro Madriz emitiera el Reglamento Orgánico del Consejo de 
Instrucción Pública en 1849, que vino a regular por primera vez en forma unificada la materia educativa, incluso respecto a las escuelas primarias, cuyos maestrosdirectores eran nombrados por una Junta Provincial de Instrucción Pública -antecedente de las Juntas de Educación establecidas luego por distrito escolar en la reforma de Mauro Fernández de 1886-, y el artículo 236 de dicho reglamento disponía que dicha designación se hacía "previo examen presentado ante ella o ante la persona que designare" y que debía recaer en persona honrada y de moralidad conocida -art. 238-. A su vez, cabía la destitución por mala conducta o negligencia y era propuesta por la respectiva Junta Provincial al Consejo de Instrucción Pública, que venía entonces a ser el superior, órgano este último en donde curiosamente el ministro de gobierno no tenía asiento. Integraban ese Consejo seis miembros: el Director General, el Rector, Vicerrector, el Secretario de la Universidad y dos miembros más, nombrados por el Gobierno -art. 2- y se entendían por medio del Secretario de la Junta Provincial -art. 252-.

Dicho Reglamento rigió durante 20 años en lo que corresponde a la Instrucción Primaria, ya que para 1869 un importante cambio constitucional se produce con la nueva Carta Magna de ese año, al introducirse como parte de la misma un Título Cuarto dedicado a la Educación, que constaba de dos artículos -el 6 y 7-, cuyo ordinal sexto elevó a rango constitucional la gratuidad de la enseñanza en la escuelas -que ya disponía el art. 234 del Reglamento Orgánico de 1849-, reforzó la compulsión escolar al darle el carácter obligatorio y señaló que es "costeada por la Nación", con lo cual el Gobierno Central asume la responsabilidad principal -aunque no exclusiva- en su sostenimiento financiero, liberando la obligación que pesaba en los fondos municipales, las cuales quedaron facultadas pero no obligadas a contribuir con la educación, situación similar a la de los particulares que voluntariamente desearan contribuir.
Nueve meses más tarde, el Presidente Jesús Jiménez emite el Reglamento de Instrucción Pública (Decreto LXX del 10 de noviembre de 1869), que constituye el segundo esfuerzo unificador y revitalizador de los distintos niveles de enseñanza en nuestro país, en donde aunque se mantuvo la dirección y manejo de la enseñanza primaria a cargo de las Municipalidades, a las cuales correspondía hacer las propuestas para los nombramientos de maestros al Poder Ejecutivo -art. 1 inciso 9-, producto de concursos por oposición por escrito, debidamente publicitados -art. 53 y siguientes-. Asimismo, los Ayuntamientos podían sancionar a los maestros, pero la destitución se reservaba como competencia exclusiva del Poder Ejecutivo -art. 90-.

Con la Constitución de 1871 se facultó al Presidente de la República a nombrar y remover libremente a todos los empleados pagados por el erario público, maestros incluidos, y con la Ley General de Educación Común de 1886 promulgada estando en vigencia esa Constitución se reguló lo relativo al personal docente en el Capítulo XI, disponiéndose requisitos de idoneidad técnica, moral y física para acceder a cargos docentes -art. 43-, se reguló el tratamiento de la inopia -art. 46- y se determinó que "los maestros nombrados permanecerán en su puesto por todo el tiempo de su buen desempeño a juicio del Poder Ejecutivo" -art. 46-.

Veinte años más tarde, en 1906 el Presidente Cleto González Víquez dictó al amparo de la potestad reglamentaria dispuesta por el artículo 152 de la Ley General de Educación Común el "Reglamento Orgánico del Personal Docente de las Escuelas Comunes", el cual vino a significar un encomiable esfuerzo por dotar de estabilidad a los maestros, ya que su artículo 46 dispuso que eran inamovibles en el tanto “...conservaran el cargo mientras dure su buena conducta y sus aptitudes físicas y profesionales", señalando en el artículo siguiente una lista taxativa de las causales o supuestos comprendidos bajo 
el término "aptitud física y profesional" así como buena conducta.

Los estudiosos de este tema -como Celín Arce y Wilburt Jiménez- con acierto señalan que dicho ordinal constituye un primer precedente conducente a librar a los maestros de los vaivenes políticos, y con ello dignificar la profesión, ya que incluso el propio numeral 46 los deja exentos de todo servicio militar y de policía, facilitando la plena dedicación y necesaria continuidad a tan importante labor.

Lo que sucedió fue que, jurídicamente hablando, dicho reglamento contravenía la disposición contenida en la Constitución entonces vigente -la cual mencionamos supra- respeto a las atribuciones del Presidente de la República para nombrar y remover libremente a los empleados públicos, aspecto señalado posteriormente por el Presidente Ricardo Jiménez Oreamuno, reivindicando la aplicación directa de la Constitución como norma suprema y la desaplicación de dicho reglamento en ese aspecto tan vital.

En todo caso, a partir del Reglamento de 1906 y luego por la Ley Orgánica del Personal Docente emitida en el año 1920, los nombramientos de los docentes se comenzaron a practicar con un más acendrado sentido técnico gracias a que se contaba con un mayor número de maestros "titulados", e incluso con la participación -recomendación- de los inspectores del circuito escolar respectivo -art. 4-. Además, existía una Junta Calificadora de Personal Docente que asignaba categorías conforme a una hoja de servicios con los antecedentes de cada maestro, acordaba ascensos, redactaba los exámenes de quienes deseaban obtener un certificado de aptitud, etc., presidida por el Jefe de Educación Primaria, una suerte de Jefe de Personal de aquel entonces.

Dicha ley confería la propiedad de la plaza durante el curso lectivo a quienes fueran nombrados y estuvieran inscritos en el Escalafón de Maestros de la República -art. 4-, y repitió en su ordinal 77 el 46 del Reglamento de 1906, pero eliminando la palabra "inamovibilidad". En relación a los aspirantes se dispuso que "únicamente tendrá derecho a conservar su plaza por todo el curso lectivo aquellos cuyos buenos servicios les hagan acreedores a esa prerrogativa".

Veinticuatro años después, los artículos 107 y 22.14 del Código de Educación (Ley 181 del 18 de agosto de 1944) disponían que los nombramientos docentes los hacía el Ministro de Educación, de acuerdo con propuestas de los inspectores respectivos, que se canalizaban a través de una suerte de jefe de personal denominado Jefatura Administrativa de Educación Primaria. Asimismo, los ascensos y clasificación de los docentes se continuaron realizando a través de una Junta Calificadora -art. 114 y siguientes-.

\section{Segundo período}

No fue sino con la Constitución de $1949^{3}$ - la cual reemplazó a la de 1871que se modificó la amplia atribución del Presidente de la República de nombrar y remover libremente a los empleados públicos, al sujetar para la gran mayoría de los funcionarios -incluidos los docentes-a que el inicio y el fin de la relación de servicio esté sujeto a las normas y principios de un régimen de méritos (art. 140 inciso 1 y numerales 191 y 192), lo que dio pie a la promulgación del Estatuto de Servicio Civil (Ley No. 1581 de 30 de mayo de 1953).

La implantación de dicho régimen significó un largo, paulatino e inacabado proceso de cambio en toda la Administración Pública, de un sistema de botín político a uno regido por el mérito y la capacidad, lo cual históricamente ha tenido que recorrer por un camino nada fácil, ya que el nepotismo culturalmente arraigado no se erradica o estirpa sin oposición.

Así, las disposiciones en materia de nombramientos contenidas en el Código de Educación fueron derogadas por el artículo 51 del Estatuto de Servicio Civil de 1953 
en lo que se opusiere, y el artículo 7 de ese Estatuto que obligó al Presidente de la República y a los Ministros a sujetarse a las normas de Servicio Civil, aspecto que reforzó posteriormente el artículo 18 inciso ch) de la Ley Orgánica del MEP (Ley No. 3481 de 13 de enero de 1965), y en concreto distribuyó a lo interno de esa cartera las competencias en esta materia en el Departamento de Personal -artículo 47 y siguientes-, fungiendo como colaborador con la Dirección General de Servicio Civil en la selección del personal docente y administrativo con sujeción a los requisitos que la ley establece.

Cabe destacar que si bien los principios y disposiciones de este Estatuto abarcaron a todos los servidores del Poder Ejecutivo, incluidos los docentes, brindándoles un sistema de acceso, carrera

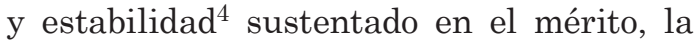
capacidad y la profesionalización, la generalidad de dicho Estatuto en un principio no contempló las particularidades del servicio educativo, aspecto que mereció ajustarse mediante la Ley de Carrera Docente -en adelante LCD-, ya que dos terceras partes del personal amparado a dicho régimen son docentes.

En ese sentido, el paso más audaz y avanzado que se ha producido en esta materia, se produjo con la promulgación de la Ley de Carrera Docente (Ley No. 4565 de 4 de mayo de 1970), ya que se creó un régimen propio y específico para el personal del magisterio nacional, con fines muy apropiados y todavía enteramente vigentes como los que se desprenden del artículo 53, entre los cuales destacamos el dignificar al educador así como obtener que todo ascenso o mejoramiento sea exclusivamente con base en sus méritos y antecedentes.

El empeño en el mérito y la capacidad quedaron reflejadas en múltiples normas: primero, la creación de la figura de los jurados asesores para determinar las bases o criterios de selección -artículos 87 y siguientes- que sobre una base de participación opera como una garantía de objetividad y transparencia en el proceso de reclutamiento, calificación y selección; segundo, la novedad -única en el empleo público costarricense- de desechar la terna y la tradicional discrecionalidad que la caracteriza, sustituyéndola simplemente por el mejor calificado que concurse por la plaza -artículo $83 \mathrm{c}$-), siempre que las vacantes no deban ser ocupadas primero para reajustes por reducción forzosa de matrícula que haya afectado a un docente que goza de propiedad o la prioridad de completar lecciones que tiene un docente titular de un número menor a las 32 lecciones en propiedad que señala el párrafo segundo del artículo 15 de la Ley de Salarios de la Administración Pública (Ley No.2166 de 9 de octubre de 1957 y sus reformas). En tercer lugar, cabe destacar la creación de un Tribunal Administrativo propio para atender los asuntos del personal docente, entre cuyas competencias claramente aparece el conocer y resolver los reclamos por el no reconocimiento de los derechos del personal docente, incluso cuando son resoluciones del Departamento de Personal del MEP, agotando la vía administrativa -art. 81 de la LCD-.

Esta norma incluso se encuentra reforzada por el artículo 5 de la Ley No. 4770 del 13 de octubre de 1972 que señala: "en todos los casos, en igualdad de condiciones se preferirá al profesor con título más elevado".

Una vez repasado por el marco legal y administrativo antes señalado, nos proponemos en el siguiente apartado puntualizar los aspectos claves que han venido en los últimos años limitando seriamente los avances en esta materia, aspectos de cuya adecuada atención y sostenido cambio depende la solución de la problemática que nos ocupa.

\section{Problemas prácticos}

En este apartado, se pretende puntualizar los principales obstáculos que en la historia reciente podemos identificar para lograr el efectivo cumplimiento de un 
verdadero sistema de méritos en el colectivo de los servidores docentes.

Trataremos los temas relacionados con: la figura del encargado de nombramientos, los registros de elegibles para nombramientos interinos en cada regional, los problemas de gestión y control del MEP en esta materia, los abusos en los traslados y ascensos por excepción, la indispensable revitalización del Tribunal de Carrera Docente y la idoneidad que debe comprobarse de quienes aspiran a ocupar cargos docentes.

\section{a. Encargado de nombramientos y registro de elegibles}

Cada cuatro años, en cada nueva Administración se designaba libremente para cada una de las veinte direcciones regionales del MEP a un servidor denominado "Encargado de nombramientos", quien era el responsable de tomar las decisiones sobre los nombramientos docentes de esa región, y en la práctica también fungía como un "enlace" entre el diputado de la zona con el MEP para esos efectos.

La operación del sistema de nombramientos actual se rige por el artículo 96 de la LCD, el cual establece lo que debe hacerse cuando se produce una vacante definitiva o temporal, en donde si se trata de una vacante definitiva o temporal superior al año, se debe llenar conforme al orden descendente del registro de elegibles, mientras que si la vacante es temporal y por lo que resta del curso lectivo, son las autoridades del MEP las que deben nombrar al interino del sustituto más idóneo, de entre el personal calificado que se encuentre en el Registro de Elegibles.

En la práctica, por muchos años esta disposición dio lugar a la existencia de dos registros de elegibles que funcionaban paralelamente, uno para nombramientos en propiedad y otro para nombramientos interinos, situación que fue objetada por la Contraloría General de la República, mediante el informe de fiscalización titu- lado "Transparencia en el nombramiento interino de docentes: uno de los retos del MEP en el siglo XXI", el cual da cuenta de que en el año 2002 habían 47.346 docentes nombrados en el MEP, de los cuales 19.600 estaban interinos (41,40\%), con el agravante de que desde hacía más de 30 años venía operando la figura del "Encargado de nombramientos" en cada Dirección Regional, elegidos por los políticos de la cabecera de provincia a que pertenece cada regional, facilitando la nefasta institucionalización de prácticas nocivas e inconvenientes en los nombramientos y el funcionamiento de registro de elegibles para nombramientos interinos en cada regional, con el riesgo de designaciones dobles, nepotismo, favoritismo, descontrol -incluso por nombramientos fantasmas-, etc.

Recuérdese que históricamente cada año los nombramientos interinos docentes se cuentan por miles, y, sin embargo, es sabido que su manejo fue libremente manipulado, pero la intervención de dos instituciones ha venido a significar un cambio que se perfila como irreversible: primero, la Sala Constitucional a inicios de los noventas abolió la ampliamente difundida práctica de quitar a un interino por poner a otro ${ }^{5}$-aunque aún persistenten algunos focos como lo demuestran recursos de amparo que se continúan interponiendo y ganando, aunque en mucho menor número-; segundo, la Contraloría General de la República estudió el tema en el informe antes citado de finales del año 2002, y gracias a su intervención se eliminó la ilegal figura del Encargado de Nombramientos y se ordenó utilizar un solo registro de elegibles, tanto para los nombramientos en propiedad como los interinos, aspecto ratificado por la Procuraduría General de la República en su dictamen C-287-2005 del 8 de agosto de 2005, con la cual se proscribe la discrecionalidad con que se venía funcionando en la materia y se coloca a las autoridades del MEP ante la inexcusable obligación de adecuar sus sistemas y base 
de datos a esta exigencia, sin que motivos de "conveniencia" y "oportunidad" puedan ser alegados.

\section{b. Problemas de gestión y control del MEP}

En el MEP no ha habido orden ni transparencia en el manejo de las vacantes y en los nombramientos, primero por una razón objetiva: la voluminosidad sin igual de la planilla ha hecho muy difícil su manejo y su control -más de 60.000 servidores-y la complejidad de su administración - miles de centros de trabajo esparcidos por todo el territorio nacional y con un sistema salarial muy complicado-; segundo, por una razón más importante y más de fondo: la falta de voluntad política así como las erráticas decisiones de una y otra administración para dotar de una buena organización y recursos a la Dirección de Administración de Personal, lo mismo que de un moderno sistema integrado de recursos humanos en red, base de toda reforma en esta materia, el cual todavía al día de hoy no se tiene operando efectivamente, pese a haberse gastado cientos de millones de colones en los últimos diez años en esfuerzos mal acabados, pues debe hacerse un rediseño total y útil para estos propósitos, tal y como lo ha venido señalando insistentemente la propia Contraloría General de la República.

Actualmente, la traba que persiste para implementar la transparencia, el control y la regularidad jurídica en los nombramientos es de orden meramente administrativa y tecnológica, dado que los sistemas utilizados por el MEP aparecen como poco aptos para tales propósitos y presentan muchas inconsistencias y duplicidades, tanto en los órganos que intervienen (Dirección General de Personal y de Informática) como en los sistemas propiamente dichos (Sistema Integrado de Gestión de Recursos Humanos (SIGRH), el Sistema de Administración de Personal (SAP) y el Sistema Integrado de Recursos Humanos, Planillas y Pagos (INTEGRA) del Ministerio de Hacienda, sumando la relación de puestos que por aparte realiza el Departamento de Programación Presupuestaria), de manera que una solución moderna, integrada, completa y definitiva se impone como urgente y prioritaria.

Sería injusto dejar de señalar que la Dirección General de Personal -al igual que casi todas las dependencias del MEP-, trabaja en condiciones inadecuadas para dar un buen y eficiente servicio a los docentes y las docentes, malas condiciones que se reflejan en la incómoda infraestructura física, en la inestabilidad que se viven cada cambio de gobierno, en que no se cuenta con hardware apropiado y mucho menos un sistema electrónico de expedientes de personal, etc. Todos éstos aspectos repercuten negativamente no sólo en la gestión y el control, sino en la educación como tal, debido a que los educadores suelen trasladarse a San José para realizar sus gestiones, con descuido de su labor en el aula, aunque claro, no se tienen registros o estadísticas, pero esto ha sido y es público y notorio.

No existe una explicación racional acerca de cómo uno de los Ministerios más antiguos e importantes para el desarrollo nacional no posee su propio edificio, amplio, moderno, funcional, que concentre y facilite la gestión de todas sus dependencias, en donde opere una plataforma de servicios adecuada y se emprenda la tarea de un rediseño total de su aquilosada, dispersa y fragmentada estructura orgánicofuncional. Creo que todos estaríamos muy felices si el nuevo Ministro de Educación se abocara a estudiar y trabajar estos impostergables asuntos.

\section{c. Traslados y ascensos por excepción: una burla al sistema de méritos}

Históricamente tenemos que decir que se ha aplicado mal el necesario mecanismo de los traslados y ascensos por excepción previstos por el artículo 101 de la LCD y 56 y siguientes de su Reglamento, 
vía que algunos educadores utilizan con fraude de ley mediante certificados médicos irregulares para conseguir una plaza en propiedad en un centro educativo o localidad más atractiva.

¿Cómo puede operar el fraude? Un educador consigue un certificado médico y plantea en los plazos que señala el MEP cada año para estos movimientos, una solicitud de traslado por excepción, luego de averiguar cuáles plazas atractivas están quedando vacantes por jubilación, renuncia, etc. Entonces el mecanismo del traslado o ascenso como regla que señala la LCD puede quedar burlado, con la complicidad de algunos médicos, de manera que el mérito y la capacidad esperan para otro momento. Claro que mucho se puede hacer si la aplicación se hace en forma restrictiva, exigiendo un claro e irrefutable nexo de causalidad entre la enfermedad y la localidad donde opera el centro educativo, o bien, si se trata de fuerza mayor velar porque se comprueben circunstancias de ese tipo.

También, en el caso de ascensos directos de puestos administrativo-docentes y técnico-docentes al aplicárseles las reglas del Título I del Estatuto de Servicio Civil se promueve el favoritismo, y no se cumple la norma que manda a que los mismos se hagan conforme a la antigüedad, calificación de servicios, calificación profesional, etc., en vista de que simplemente se constata que el aspirante posea los requisitos que el puesto exige pero no suele repararse en esos parámetros legales, situación que opera aún en el caso de un Director de Enseñanza General Básica 1 (unidocente), el cual siempre había sido considerado docente y no administrativo-docente, situación que favorece los ascensos sin concurso y el favoritismo.

A finales de los años noventa se presentó un proyecto de Ley (Expediente No. 12783) llamado "Despolitización de los movimientos de personal del Magisterio Nacional (reforma artículo 101 ESC)", el cual pretendía eliminar los traslados, ascensos y descensos por motivos de enfermedad, reajuste de matrícula y situaciones conflictivas, a fin de que en todo caso se aplicaran los trámites concursales ordinarios.

Cabe señalar que del proyecto se dio traslado a los gremios de educadores -sólo el SEC se manifestó apoyándolo-, en tanto que la Dirección General de Servicio Civil se pronunció por una revisión y actualización más amplia, pero al final de cuentas la Comisión de Asuntos Sociales de la Asamblea Legislativa dió un dictamen unánime negativo en el año 1998, indicando que se trataba de un parche y que en la corriente existía un proyecto de ley de empleo público.

Este es un ejemplo de una iniciativa legislativa llena de buenas intenciones pero alejada de la realidad, que no atina a resolver el problema de fondo y que más bien lo hubiera agravado, al impedir que se aplique a casos verdaderamente justificados. La solución pasa por hacer valer los principios de publicidad, transparencia, mérito y capacidad, con instancias de revisión imparciales, efectivas y ágiles.

\section{d. La revitalización del Tribunal de Carrera Docente}

Para nadie es un secreto las limitaciones de recursos humanos, materiales, tecnológicos y jurídicos con que opera el Tribunal de Carrera Docente y la consiguiente lentitud endémica en su funcionamiento, acerca de lo cual tampoco hay estadísticas, pero por experiencia propia sé que tal situación es pública y notoria.

La justicia en el nombramiento de los educadores y el efectivo cumplimiento de la Ley de Carrera Docente pasa por el fortalecimiento presupuestario y normativo de este Tribunal Administrativo, cuyos miembros trabajan por sesiones, pero si el MEP lo dotara de suficientes recursos en lo administrativo, profesional, tecnológico y financiero presupuestario, lo cual agilizaría en gran y extraordinaria manera su importante trabajo. 
$\mathrm{Y}$ es que por años ha operado con una secretaria, sin notificador, con uno o dos abogados y prácticamente sin equipo de cómputo, recursos, etc. Además, su mayor trabajo hasta ahora se ubica en la parte disciplinaria y luego en reclamos por calificaciones anuales de servicio y pugna por recargos salariales, pero muy poco ha conocido sobre reclamos de docentes por considerar que tenía un mejor derecho para obtener un nombramiento y ocupar una plaza, lo cual puede obedecerse a ignorancia o a la falta de confianza sobre la efectividad y agilidad del Tribunal.

En ese sentido, bien podría aprovecharse el mandato que deriva de la resolución No. 6866-05 del primero de junio de 2005 de la Sala Constitucional que proscribió las atribuciones legales del Poder Judicial como jerarca impropio en materia de pensiones y función pública, para plantear un proyecto de ley que transforme al Tribunal de Carrera Docente en instancia única -es decir, que no haya necesidad de acudir al Tribunal de Servicio Civil con lo que se agiliza la justicia administrativa-, designando jueces a tiempo completo y con las demás atribuciones ya mencionadas, de manera que se tenga garantía de pleno cumplimiento de la Ley de Carrera Docente.

\section{e. La idoneidad del docente debe comprobarse con más rigurosidad}

Hay que reconocer que las autoridades del Servicio Civil siempre han realizado ingentes esfuerzos por mejorar lo relativo a la comprobación del mérito y capacidad de quienes pretenden ingresar a ejercer la función pública docente. Sin embargo, persisten marcadas limitaciones de personal, financieras y operativas para realizar un mejor trabajo en materia de reclutamiento y selección de docentes.

Dos casos están vivos en mi memoria y son paradigmáticos para entender por qué las leyes no son excusa, cuando de imponer la moral y la técnica en los nombramientos docentes se refiere.
El primero, tiene que ver con personas con condenas pendientes de cumplir por violaciones y abusos deshonestos que trabajan por primera vez o han sido recontratados como docentes en el MEP según ha dado cuenta la prensa en los últimos meses $^{6}$, en donde no hay un control para evitar que tan lamentable y peligrosa situación se produzca, porque pese a que los artículos 20 inciso a) y 55 inciso a) aparte 5 del Estatuto de Servicio Civil exigen como mecanismo de comprobación de la idoneidad moral el certificado que expide el Registro Judicial de Delincuentes del Poder Judicial, tal requisito no ha sido exigido en los últimos años por las autoridades del MEP ni del Servicio Civil.

Claro que la legislación puede mejorar. Podemos poner como ejemplo Inglaterra, en donde recientemente se aprobó una legislación que impide que los pederastas, es decir, personas condenadas o amonestadas por delitos sexuales relacionados con niños ocupen empleos relacionados con menores, particularmente en el sector educativo ${ }^{7}$.

El segundo caso que podemos poner como ejemplo está asociado con la idoneidad técnica y tiene que ver con los profesores de inglés, los cuales venían siendo evaluados en el dominio del idioma y la mayoría reprobaba año con año las pruebas que se practicaban. Es decir, se tenía una prueba muy palpable de las deficiencias de su formación universitaria recibida, hecho que debió "poner las barbas en remojo" en las instituciones públicas y privadas de educación superior que estaban graduando profesionales no idóneos. Pues bien, esas pruebas desde hace dos años no se realizan, salvo en los Colegios Bilingües y para nombramientos en propiedad y no interinos, de manera que es muy probable que muchos profesores hayan alcanzado su propiedad sin acreditar el dominio del idioma, pese a que las clases de inglés suelen ser presentadas como uno de los programas estrella junto con el de informática en el currículo educativo público.

Se trata sólo de ejemplos, pero existen muchas otras áreas de mejora en los proce- 
sos técnicos y administrativos que rigen el sistema de nombramientos docentes, las cuales han de ser identificadas, priorizadas y mejoradas, con base en los principios de transparencia, publicidad, justicia, idoneidad, igualdad y no discriminación y eficiencia, todos de raigambre constitucional.

\section{Conclusiones}

1. La calidad de la educación y la dignidad del educador están en juego si no se resuelven los problemas de favoritismo, falta de transparencia y politiquería en los nombramientos, cuyos males son ciertamente muy antiguos.

2. La solución a estos males, contrario a lo que algunos puedan pensar, no pasa en primer lugar por cambios legales, sino por el compromiso y el interés por llevar adelante condiciones de funcionamiento que garanticen un ambiente favorable a la ética en la función pública de parte de las autoridades del MEP, del Servicio Civil y las Hacendarias, de modo que se redoblen esfuerzos para hacer cumplir los principios y leyes, así como mejorar los procedimientos y sistemas de información existentes, dotando de mayores recursos humanos, tecnológicos, físicos y financieros a la Dirección de Personal, a las Direcciones Regionales, al Tribunal de Carrera Docente y al mismo Departamento de Carrera Docente del Servicio Civil.

3. Los planes de estudio en las universidades deben ser revisados, lo mismo que la labor del Centro Nacional de Didáctica (CENADI), los gremios de educadores y el Colegio de Licenciados y Profesores en Letras, Filosofía, Ciencias y Artes (COLYPRO) en punto a los cursos de legislación educativa, ya que es palpable el desconocimiento de los docentes en ésta materia que la gran mayoría de uni- versidades no tienen como parte del curriculum, por lo que es necesario que los propios docentes sean protagonistas y aboguen ilustradamente por sus propios intereses.

4. Siempre es posible mejorar las leyes, y de hecho hemos planteado algunos ajustes principalmente en la integración y competencias del Tribunal de Carrera Docente, pero los instrumentos jurídicos actuales son suficientes para remediar muchos de estos males, siempre que sean rectamente aplicados e interpretados, sin necesidad de una reforma integral a toda la Ley de Carrera Docente, sino simplemente algunos aspectos más puntuales como lo que se han señalado.

\section{Notas}

1 Este trabajo tiene como base la ponencia base presentada en el mes de marzo de 2006 ante el foro abierto de la Comisión de Revisión y Actualización Jurídica nombrada por el Consejo Superior de Educación, con motivo del proyecto de Relanzamiento de la Educación Costarricense.

2 Por ejemplo, desde el finales del año 2003 las cartas de recomendación de diputados y de otros altos cargos públicos para influir en los nombramientos son penalizadas por el artículo 52 de la Ley contra la Corrupción y el Enriquecimiento Ilícito (Ley No. 8422 del 6 de octubre de 2004), pero la presión por los nombramientos puede adquirir o revestirse de otras muchas formas y obtener idénticos resultados: llamadas telefónicas, conversaciones, etc. Incluso la nueva Administración Sánchez designó a un Director General de la Fuerza Pública quien no reúne los requisitos que dispone el Estatuto Policial para ocupar ese cargo, otorgándose un plazo para que los completara...

3 En realidad, en este punto la Constitución de 1871 había sido modificada en el año 1946 para introducir el Servicio Civil, pero el Estatuto que permitiría hacer realidad dicha aspiración nunca se emitió en ese entonces.

4 Esta se reforzó con lo dispuesto por los artículos 38, 39 y 40 de la Ley Fundamental de Educación (Ley No. 2160 de 21 de octubre de 1957).

$5 \quad \mathrm{Al}$ respecto puede consultarse mi artículo "Los nombramientos interinos docentes en la 
jurisprudencia constitucional", publicado en la Revista IUSTITIA, Año 16, No. 181-182, enero-febrero de 2002.

Puede consultarse el Editorial del periódico La Nación del 6 de enero de 2006, en donde incluso se da cuenta que un asesor legal del MEP afirma que "no existe norma alguna que impida a un exconvicto solicitar su ingreso al Magisterio", cuando el problema no reside en la gestión en sí, sino en la atención y respuesta que la misma reciba por parte de las autoridades competentes, ya que para eso existen los estudios de Vida y Costumbres, por parte de una Comisión interdisciplinaria que debe ser la que valore este tipo de casos, como derivación directa incluso del principio constitucional de idoneidad comprobada y del principio del interés superior del menor que informa esta materia conforme a las disposiciones del Código de la Niñez y la Adolescencia.

7 Información tomada del periódico La nación, página 25 a del 21 de enero de 2006.

\section{Referencias bibliográficas}

Colección de Leyes y Decretos. Imprenta Nacional. 1841 a 2006. 